\title{
Mechanisms Underlying Developmental Speeding in AMPA-EPSC Decay Time at the Calyx of Held
}

\author{
Maki Koike-Tani, Naoto Saitoh, and Tomoyuki Takahashi \\ Department of Neurophysiology, University of Tokyo Graduate School of Medicine, Tokyo 113-0033, Japan
}

The time course of synaptic conductance is important in temporal precision of information processing in the neuronal network. The AMPA receptor (AMPAR)-mediated EPSCs at the calyx of Held become faster in decay time as animals mature. To clarify how desensitization and deactivation of AMPARs contribute to developmental speeding of EPSCs, we compared the decay time of quantal EPSCs (qEPSCs) with the deactivation and desensitization times of AMPAR currents induced in excised patches by fast glutamate application (AMPA patch currents). Both the deactivation and desensitization times of AMPA patch currents became markedly faster from postnatal day 7 (P7) to P14 and changed little thereafter. In individual neurons, throughout development (P7-P21), the time constants of deactivation and fast desensitization in AMPA patch currents were similar to each other and close to the qEPSC decay time constant. Cyclothiazide (CTZ) abolished the fast desensitization, prolonged deactivation of AMPA patch currents, and slowed the decay time of EPSCs. The effects of CTZ on AMPA patch currents were unchanged throughout development, whereas its effect on EPSCs became weaker as animals matured. In single-cell reverse transcription-PCR analysis, glutamate receptor subunit 4 (GluR4) flop increased from P7 to P14 and changed little thereafter. At P7, the GluR4 flop abundance had an inverse correlation with the qEPSC decay time. These results together suggest that both desensitization and deactivation of AMPARs are involved in the EPSC decay time, but the contribution of desensitization decreases during postnatal development at the calyx of Held.

Key words: EPSC; AMPA receptor; desensitization; deactivation; postnatal development; single-cell RT-PCR

\section{Introduction}

Developmental speeding in the decay time of synaptic currents is commonly observed at both excitatory (Sakmann and Brenner, 1978; Fischbach and Schuetze, 1980) and inhibitory (Takahashi et al., 1992; Okada et al., 2000) synapses. At the excitatory synapse, speeding of the synaptic current decay contributes to faster rising EPSPs and reduced spike jitter, thereby increasing the temporal precision of synaptic transmission (Galarreta and Hestrin, 2001; Cathala et al., 2003), which is essential for accurate sensory perceptions, organized motor movements, and cognition. Developmental switches of postsynaptic receptor subunits underlie speeding in the decay time of synaptic currents mediated by nicotinic acetylcholine receptors (Mishina et al., 1986), glycine re-

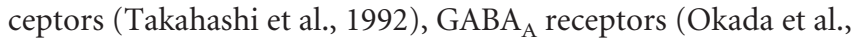
2000), and NMDA receptors (NMDARs) (Monyer et al., 1994; Takahashi et al., 1996). Like other synaptic currents, the decay time of AMPA-EPSCs at the calyx of Held becomes faster during postnatal development (Taschenberger and von Gersdorff, 2000; Futai et al., 2001; Iwasaki and Takahashi, 2001; Joshi and Wang, 2002; Wall et al., 2002; Yamashita et al., 2003). However, it is not

Received Sept. 17, 2004; revised Nov. 18, 2004; accepted Nov. 18, 2004.

This work was supported by a Grant-in-Aid for Specially Promoted Research from the Ministry of Education, Culture, Sports, Science, and Technology. We thank S. Heinemann for providing us CDNAs for glutamate receptor and Keisuke Tsuzuki for technical advice on the single-cell reverse transcription-PCR. We also thank Shizuka Seino for technical assistance and Seiji Ozawa and Angus Silver for comments on this manuscript.

Correspondence should be addressed to Tomoyuki Takahashi, Department of Neurophysiology, University of Tokyo Graduate School of Medicine, 7-3-1 Hongo, Bunkyo-ku, Tokyo 113-0033, Japan. E-mail: ttakahas-tky@umin.ac.jp. DOl:10.1523/JNEUROSCI.3861-04.2005

Copyright $\odot 2005$ Society for Neuroscience $\quad$ 0270-6474/05/250199-09\$15.00/0 known whether the switch of AMPA receptor (AMPAR) subunits underlies this developmental speeding.

At synapses, where transmitter is rapidly cleared away from the synaptic cleft, the decay time of synaptic currents is determined primarily by the ion channel gating (Magleby and Stevens, 1972; Katz and Miledi, 1973), which is reflected in the mean burst duration of ligand-induced single-channel currents (Mishina et al., 1986; Takahashi et al., 1992, 1996; Singer et al., 1998) or the deactivation time of multiple channel currents after washout of a ligand (Silver et al., 1996). This is thought to be the main factor shaping the decay of quantal AMPA-EPSCs at the cerebral cortical (Hestrin, 1992) and cerebellar granule cell (Colquhoun et al., 1992; Silver et al., 1996) synapses. In contrast, at synapses where transmitter clearance is relatively slow and receptor desensitization is fast, the decay time of synaptic currents can be shaped by desensitization of AMPARs. Typically, at the chick auditory synapse where transmitter released from multiple sites overlaps, fast desensitization of AMPARs shapes the decay of evoked EPSCs (Trussell and Fischbach, 1989; Trussell et al., 1993; Raman and Trussell, 1995).

At glutamatergic CNS synapse, during postnatal development, the kinetics of desensitization and deactivation of AMPARs as well as the speed of transmitter clearance may all change and potentially be involved in the developmental speeding of EPSCs. In the present study, using brainstem slices of developing rats, we compared the decay time of AMPA-quantal EPSCs (qEPSCs) with the desensitization and deactivation times of AMPAR currents, induced by fast glutamate application in patches excised 
from principal neurons in the medial nucleus of trapezoid body (MNTB). Furthermore, to clarify molecular correlates after recording qEPSCs, we performed quantitative single-cell reverse transcription (RT)-PCR analysis on mRNAs harvested from postsynaptic MNTB neurons. Our results suggest that both desensitization and deactivation of AMPARs, which become faster with development, shape the decay time of qEPSCs with the former contribution decreasing as animals mature.

\section{Materials and Methods}

Preparation and solutions. All experiments were performed in accordance with the guidelines of the Physiological Society of Japan. Transverse brainstem slices (150-250 $\mu \mathrm{m}$ thick) containing MNTB were prepared from Wistar rats [postnatal day 6 (P6) to P22] that had been killed by decapitation under halothane anesthesia as described previously (Forsythe and Barnes-Davies, 1993). Slices were incubated at $36-37^{\circ} \mathrm{C}$ for 1 $\mathrm{hr}$ and then maintained at room temperature $\left(22-26^{\circ} \mathrm{C}\right)$. MNTB principal neurons were identified visually with a $40 \times$ water immersion objective (Zeiss, Oberkochen, Germany) attached to an upright microscope (Axioskop; Zeiss). The standard artificial CSF (aCSF) for perfusion contained (in mM) $125 \mathrm{NaCl}, 2.5 \mathrm{KCl}, 26 \mathrm{NaHCO}_{3}, 1.25 \mathrm{NaH}_{2} \mathrm{PO}_{4}, 2 \mathrm{CaCl}_{2}$, $1 \mathrm{MgCl}_{2}, 10$ glucose, 3 myoinositol, 2 sodium pyruvate, and 0.5 ascorbic acid, $\mathrm{pH} 7.4$ when bubbled with $5 \% \mathrm{CO}_{2}$ and $95 \% \mathrm{O}_{2}$. The aCSF routinely contained bicuculline methiodide (10 $\mu \mathrm{M}$; Sigma, St. Louis, MO) and strychnine hydrochloride $(0.5 \mu \mathrm{M}$; Sigma) to block inhibitory synaptic responses. Recording patch pipettes were filled with a solution containing (in mM) $110 \mathrm{CsF}, 30 \mathrm{CsCl}, 10 \mathrm{HEPES}, 5 \mathrm{EGTA}, 1 \mathrm{MgCl}_{2}$, and $5 \mathrm{~N}$-(2,6-diethylphenylcarbamoylmethyl)-triethyl-ammonium chloride (QX-314; Alomone Labs, Jerusalem, Israel), $\mathrm{pH}$ adjusted to 7.3 with $\mathrm{CsOH}$.

Recordings. Whole-cell recording of EPSCs and outside-out patch recording of glutamate-induced currents were made from the MNTB principal neurons using a patch-clamp amplifier (Axopatch 200B; Axon Instruments, Foster City, CA) under voltage clamp at the holding potential of $-70 \mathrm{mV}$. Patch pipettes were pulled from standard-wall borosilicate glasses (GC150F-7.5; Harvard Apparatus, Edenbridge, UK) for the resistance of 2-3 M $\Omega$. The access resistance was 4-8 M $\Omega$, which was routinely compensated by $70-80 \%$. To evoke EPSCs, a bipolar tungsten electrode for stimulation was positioned on the surface of slices halfway between the midline and the MNTB. EPSCs derived from the calyx of Held were identified as those evoked in an all-or-none manner for graded stimulus intensity and those having an amplitude $>1 \mathrm{nA}$ at $-70 \mathrm{mV}$ (Forsythe and Barnes-Davies, 1993).

Fast glutamate application. Double-barreled application pipettes were fabricated from theta glass tubes (outer diameter, $2.0 \mathrm{~mm}$; TGC200-10; Harvard Apparatus) pulled for a tip diameter of 200-300 $\mu \mathrm{m}$ (Koike et al., 2000). Control and test solutions were continuously passed through each barrel of the application pipette using static pressure. The application pipette was rapidly moved by a square voltage pulse (15-25 V, 0.7 $\mathrm{msec}$ to $1 \mathrm{sec}$ ) applied to a piezoelectric device (Burleigh Instruments, Fishers, NY). The time required for solution exchange was measured from a change in junction potential when the solution was switched from the standard aCSF to the 10 times diluted aCSF (see Fig. $1 A$ ). The 10$90 \%$ rise time and $10-90 \%$ decay time of the solution exchange was $148 \pm 7 \mu \mathrm{sec}$ and $124 \pm 10 \mu \mathrm{sec}$, respectively $(n=5)$. To block NMDARs, D-APV (50 $\mu \mathrm{M}$; Tocris Cookson, Bristol, UK) was routinely included in the aCSF.

Data analysis. All records were low-pass filtered at $5 \mathrm{kHz}$ and digitized at $50 \mathrm{kHz}$ using a Digidata 1322A analog-to-digital converter with pClamp8 software (Axon Instruments). Data of qEPSCs were stored on tape (sampling rate, $48 \mathrm{kHz}$; CDAT4; Cygnus Technology, Delaware Water Gap, PA) and analyzed off-line using Axograph software (Axon Instruments). The qEPSCs having amplitudes more than three times larger than the noise SD was accepted as a signal using the sliding template method implemented in Axograph (Clements and Bekkers, 1997). The decay time of averaged qEPSCs and the desensitization time course of AMPAR currents were fitted with double-exponential functions, and the weighted mean time constant $\left(\tau_{\mathrm{m}}\right)$ was calculated from individual time constants $\left(\tau_{\mathrm{f}}, \tau_{\mathrm{s}}\right)$ and their relative amplitudes $\left(a_{\mathrm{f}}, a_{\mathrm{s}}\right)$ as follows: $\tau_{\mathrm{m}}=a_{\mathrm{f}} \tau_{\mathrm{f}}+a_{\mathrm{s}} \tau_{\mathrm{s}}$.

All values were expressed as means \pm SEM. Statistical analysis was made using ANOVA followed by Scheffe's test, unless noted otherwise.

Single-cell quantitative RT-PCR. Patch pipettes used for the RT-PCR experiments had a resistance of 1.5-3.0 $\mathrm{M} \Omega$ when filled with the pipette solution containing an RNase inhibitor (200 U/ml; Invitrogen, San Diego, CA or Promega, Madison, WI). The glass tubes used for patch pipettes were heated at $200^{\circ} \mathrm{C}$ for $2 \mathrm{hr}$ before pulling. After recording qEPSCs, cytoplasm of an MNTB principal cell was harvested into a patch pipette. After confirming no contamination in the pipette under a microscope, we expelled all contents in the patch pipette into a tube of one-step RT-PCR reaction mixture (total volume, $50 \mu \mathrm{l}$; Amersham Biosciences, Piscataway, NJ). The reverse transcription reactions were performed using oligo(dT)12-18 (Invitrogen) and AMPAR reverse transcription primers (Sigma Genosys) at $42^{\circ} \mathrm{C}$ for $30 \mathrm{~min}$. The subsequent PCR protocol was as follows: $95^{\circ} \mathrm{C}$ for $5 \mathrm{~min} ; 25$ cycles at $94^{\circ} \mathrm{C}$ for $10 \mathrm{sec}$, $55^{\circ} \mathrm{C}$ for $10 \mathrm{sec}$, and $72^{\circ} \mathrm{C}$ for $40 \mathrm{sec}$; and $72^{\circ} \mathrm{C}$ for 3 min using a primer common for all AMPAR subunits. To quantify the amount of each AMPAR mRNA, the RT-PCR products $(1 \mu \mathrm{l})$ were analyzed with the realtime PCR method (LightCycler and PCR reaction mixture; Roche Diagnostics, Mannheim, Germany) using subunit-specific primers (Sigma Genosys) and subunit and flip/flop splice variant-specific tandem hybridization probe pairs ( $3^{\prime}$ FITC-labeled donor probes and 5' LcRedlabeled acceptor probes; Nihon Gene Research Laboratories, Miyagi, Japan). We detected the fluorescence resonance energy transfer signal of tandem probes as a proportional indicator to the amount of PCR product. The real-time PCR conditions were as follows: $95^{\circ} \mathrm{C}$ for $7 \mathrm{~min} ; 50$ cycles at $94^{\circ} \mathrm{C}$ for $10 \mathrm{sec} ; 60^{\circ} \mathrm{C}$ for $15 \mathrm{sec}$; and $72^{\circ} \mathrm{C}$ for $20 \mathrm{sec}$. To calibrate each AMPAR transcript, we used full-length AMPAR cDNA subcloned into pBluescript (generous gift from Dr. Stephen F. Heinemann, The Salk Institute, La Jolla, CA).

The AMPAR-specific reverse transcription primers were as follows: glutamate receptor subunit 1 (GluR1), CCGCTTCGACTC; GluR2, TCGTTTCGCCTC; GluR3, TGCGTTTGGACTC; GluR4, ATTCTCTTCGCCTC.

The PCR primers common for AMPAR subunits were as follows: GluR forward, TCCT(G/T)ACTGT(A/G)GAGAG(A/G)ATGGT; GluR reverse, GC(C/A)ACCA(G/T)CAT(T/G)GCC.

The subunit-specific PCR primers (nested primers) for real-time PCR were as follows: GluR1 forward, CCACAGAGGAAGGCATGATC; GluR1 reverse, GTCCCAGCCCACCAATC; GluR2 forward, CCCTCTGTGTTTGTGAGGACT; GluR2 reverse, GCCAAACCAAGGCCC; GluR3 forward, CAGAGCCATCTGTGTTTACCAA; GluR3 reverse, GGCCCAGACCTCCGAC; GluR4 forward, GCCGTCTGTGTTCACTAGAACT; GluR4 reverse, CCAAGCCCAGGCCG.

The subunit- and flip/flop-specific hybridization probes for real-time PCR were as follows: GluR1 flip probe1, GGTGGTACGATAAAGGGGAATGTG-FITC; GluR1 flip probe2, LcRed640-AAGCAAGGACTCCGGAAGTAAGGA; GluR1 flop probe1, AGGTGACTCCAAGGACAAGACC-FITC; GluR1 flop probe2, LcRed640-CGCTTTG-AGCCTCAGCAAT; GluR2 flip probe1, AATGGTGGTACGATAAAGGTGAATGTG-FITC; GluR2 flip probe2, LcRed640-AGCCAAGGACTCGGGAAGTAAGG; GluR2 flop probe1, TGGTACGACAAAGGAGAGTGCG-FITC; GluR2 flop probe2, LcRed640-CAGCGGGGGAGGTGATTC; GluR3 flip probe1, GGTGGTACGATAAGGGGGAATGTGFITC; GluR3 flip probe2, LcRed640-AGCCAAGGACTCCGGGAGTAAG; GluR3 flop probe1, GAGAGTGCGGCAGCGG-FITC; GluR3 flop probe2, LcRed640-GCGGTGACTCCAAGGACA; GluR4 flip probe1, AATGGTGGTACGATAAAGGTGAATGTG-FITC; GluR4 flip probe2, LcRed640-ACCCAAGGACTCGGGAAGC; GluR4 flop probe1, GGTGGTACGACAAAGGAGAATGTG-FITC; GluR4 flop probe2, LcRed640-AGCGGGGGAGGTGACTC.

\section{Results}

Decay time kinetics of glutamate-induced AMPAR currents After establishing an outside-out patch excised from an MNTB neuron, AMPAR currents were induced by the fast glutamate application $(10 \mathrm{~mm})$ (Fig. $1 B$ ). The decay of AMPA patch cur- 

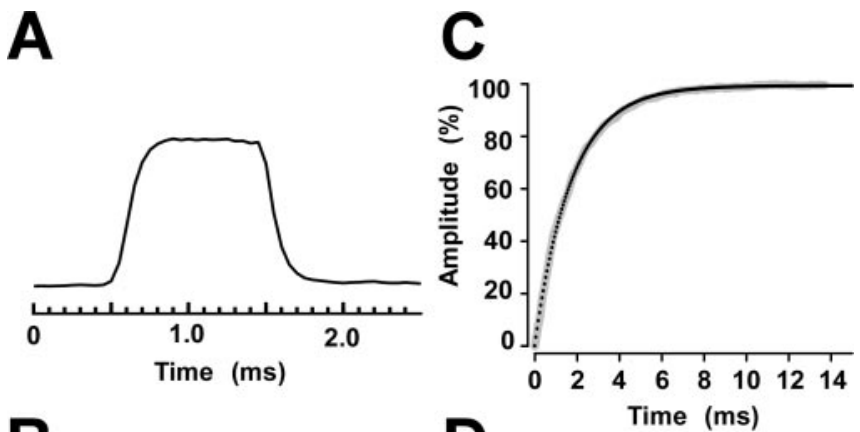

B
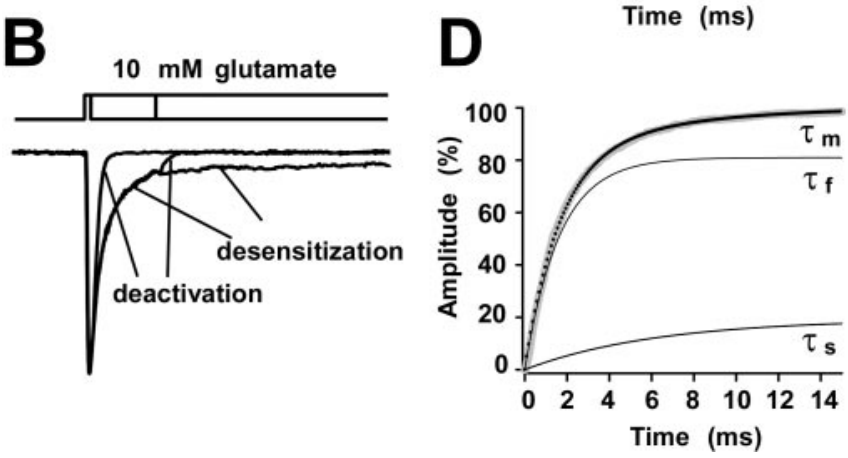

Figure 1. Glutamate-induced currents in outside-out patches excised from an MNTB neuron. $A$, An open tip response caused by a $1 \mathrm{msec}$ solution change between normal and diluted (10\%) aCSF solutions. B, Currents induced by a rapid piezoelectric application of glutamate (10 $\mathrm{mm}$ ) with a pulse of 1,10 , or $100 \mathrm{msec}$ (truncated) in duration (superimposed). The current decay during glutamate application represents desensitization, whereas those after glutamate washout represent deactivation. C, Deactivation time course (line) fitted with a singleexponential function (dots superimposed; time constant, $1.73 \mathrm{msec}$ ). D, Desensitization time course (line) fitted with a double-exponential function (in dots superimposed; $\tau_{\mathrm{m}}=2.54$ $\mathrm{msec})$. The fast $\left(\tau_{\mathrm{f}}=1.63 \mathrm{msec}\right)$ and slow $\left(\tau_{\mathrm{s}}=6.23 \mathrm{msec}\right)$ components of desensitization are shown separately (lines).

rents after brief glutamate application $(0.7-1.0 \mathrm{msec})$ arises from deactivation of AMPAR channels, and its time course could be adequately fitted with a single-exponential function (Fig. 1C). When glutamate was applied for a longer period (10 or 100 $\mathrm{msec}$ ), the patch currents declined during glutamate application because of AMPAR desensitization. The desensitization time course could be well fitted by a double-exponential function (Fig. 1D). Throughout postnatal development (P6-P22), the time course of deactivation was monoexponential, whereas that of desensitization was biexponential.

Developmental speeding of desensitization and deactivation Both the kinetics of desensitization and deactivation of AMPA patch currents became faster from P6-P7 to P13-P14 (Fig. 2). During this period, both the fast (desens $\tau_{\mathrm{f}}$ ) and slow (desens $\tau_{\mathrm{s}}$ ) time constants of desensitization became shorter $(p<0.02)$ with no significant change in their relative proportion (Fig. $2 B$ ). Similarly, the deactivation time constant $\left(\tau_{\text {deact }}\right)$ became faster (Fig. $2 D)(p<0.01)$. These results are similar to those reported recently in mice (Joshi et al., 2004). From P14 to P21, however, neither the desensitization time constants nor the deactivation time constant changed significantly (Fig. $2 B, D$ ). During postnatal development, the rise time (10-90\%) of AMPA patch currents became faster: $0.34 \pm 0.03 \mathrm{msec}$ at P6-P7 $(n=11), 0.27 \pm 0.03 \mathrm{msec}$ at P13-P14 $(n=20)$, and $0.21 \pm 0.02 \mathrm{msec}$ at P20-P21 $(n=19)$.

Comparison of AMPAR desensitization and deactivation times with the decay time of qEPSCs

We next compared the time constants of desensitization and deactivation of AMPARs with the decay time constant of qEPSCs
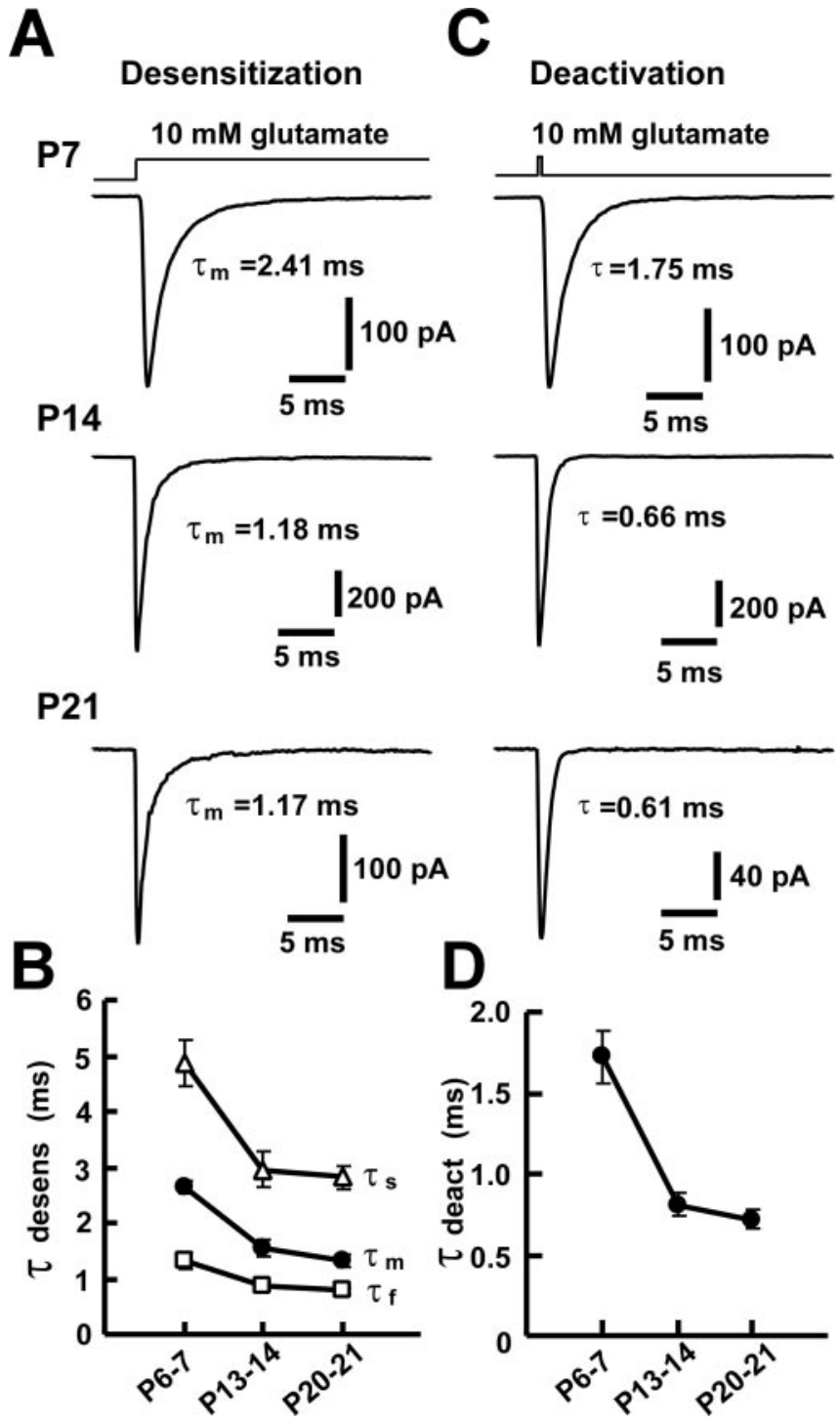

Figure 2. Developmental speeding of AMPAR desensitization and deactivation. A, AMPAR desensitization induced by a sustained (100 msec) glutamate application to outside-out patches excised from MNTB neurons of P7, P14, and P21 rats. B, Developmental speeding in the time constant of AMPAR desensitization. Fast components $\left(\tau_{f} ; \square\right)$, slow components $\left(\tau_{s} ; \triangle\right)$, and their weighted mean $\left(\tau_{m} ;\right.$ ) (see Materials and Methods) are potted at P6 -P7,P13-P14, and P20 -P21. The $\tau_{\mathrm{f}}$ was $1.31 \pm 0.16 \mathrm{msec}(n=11)$ at P6 $-\mathrm{P} 7$ and $0.86 \pm 0.07 \mathrm{msec}(n=20)$ at P13-P14 ( $p=0.01)$. The $\tau_{\mathrm{s}}$ was $4.87 \pm 0.41 \mathrm{msec}(n=11)$ at P6 $-\mathrm{P} 7$ and $2.95 \pm 0.32$ $\operatorname{msec}(n=20)$ at P13-P14 $(p<0.01)$. From P13-P14 to P20-P21, no significant change was observed for desensitization time constants: $\tau_{\mathrm{f}}=0.78 \pm 0.05 \mathrm{msec}$ and $\tau_{\mathrm{s}}=2.83 \pm 0.21$ $\operatorname{msec}(n=19)$ at P20-P21. The relative proportion of fast time constants $\left(\tau_{f} / \tau_{f}+\tau_{s}\right)$ was $58.8 \pm 7.3 \%$ at $P 6-P 7,61.7 \pm 3.4 \%$ at $P 13-P 14$, and $69.7 \pm 3.6 \%$ at $P 20-P 21$ (no statistically significant difference between ages; ANOVA). The $\tau_{\mathrm{m}}$ became significantly faster from P6 -P7 ( $2.63 \pm 0.11 \mathrm{msec})$ to P13-P14 (1.53 $\pm 0.14 \mathrm{msec} ; p<0.001)$ but not from P13-P14 to P20-P21 (1.32 $\pm 0.099 \mathrm{msec} ; p=0.43)$. C, Developmental speeding in the deactivation time constant of AMPAR currents induced by a brief glutamate pulse $(0.7-1 \mathrm{msec})$ at P7, P14, and P21. D, Developmental speeding in the deactivation time constant $\left(\tau_{\text {deact }}\right)$ from P6 $-\mathrm{P7}$ $(1.72 \pm 0.16 \mathrm{msec} ; n=11)$ to P13-P14 $(0.81 \pm 0.07 \mathrm{msec} ; n=19 ; p<0.001)$. From P14 to P21, no significant change was observed for the deactivation time constant: $\tau=0.72 \pm 0.06$ msec at P20-P21 $(n=18)$. Data points and bars indicate mean and SEM.

within the same MNTB neurons at different postnatal periods. Spontaneous EPSCs recorded from MNTB neurons mainly originate from the calyx of Held terminal and represent qEPSCs because they are indistinguishable in both frequency and amplitude 

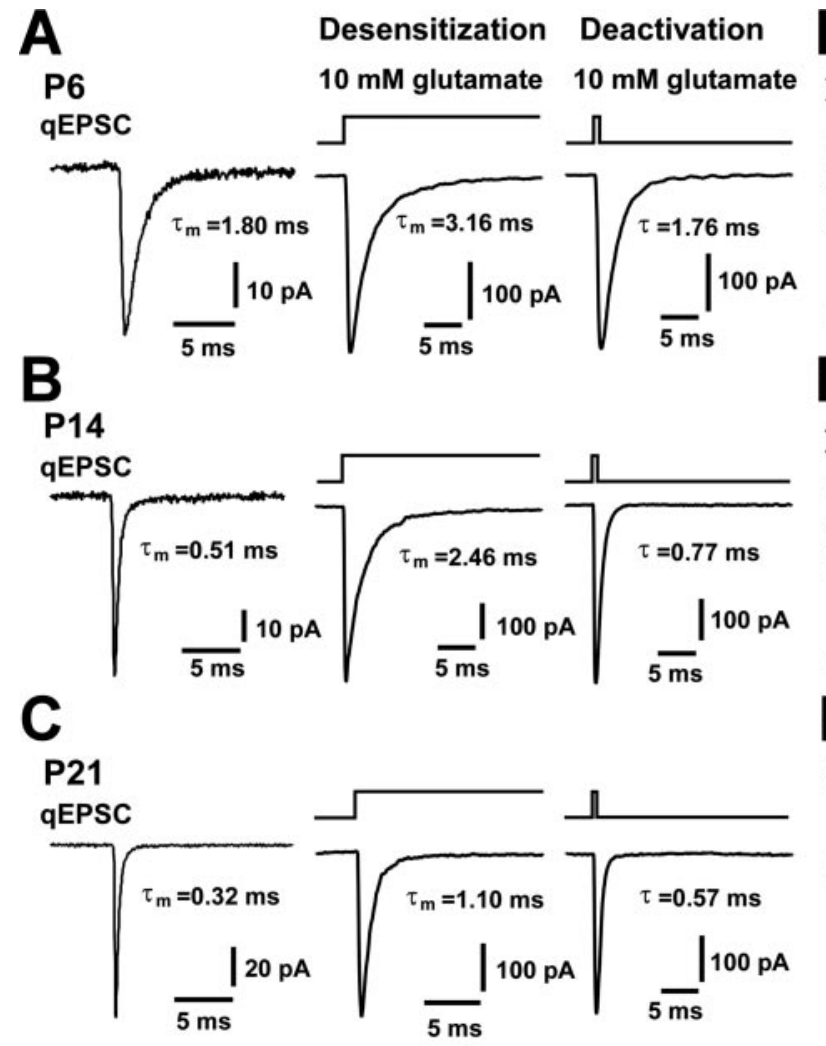
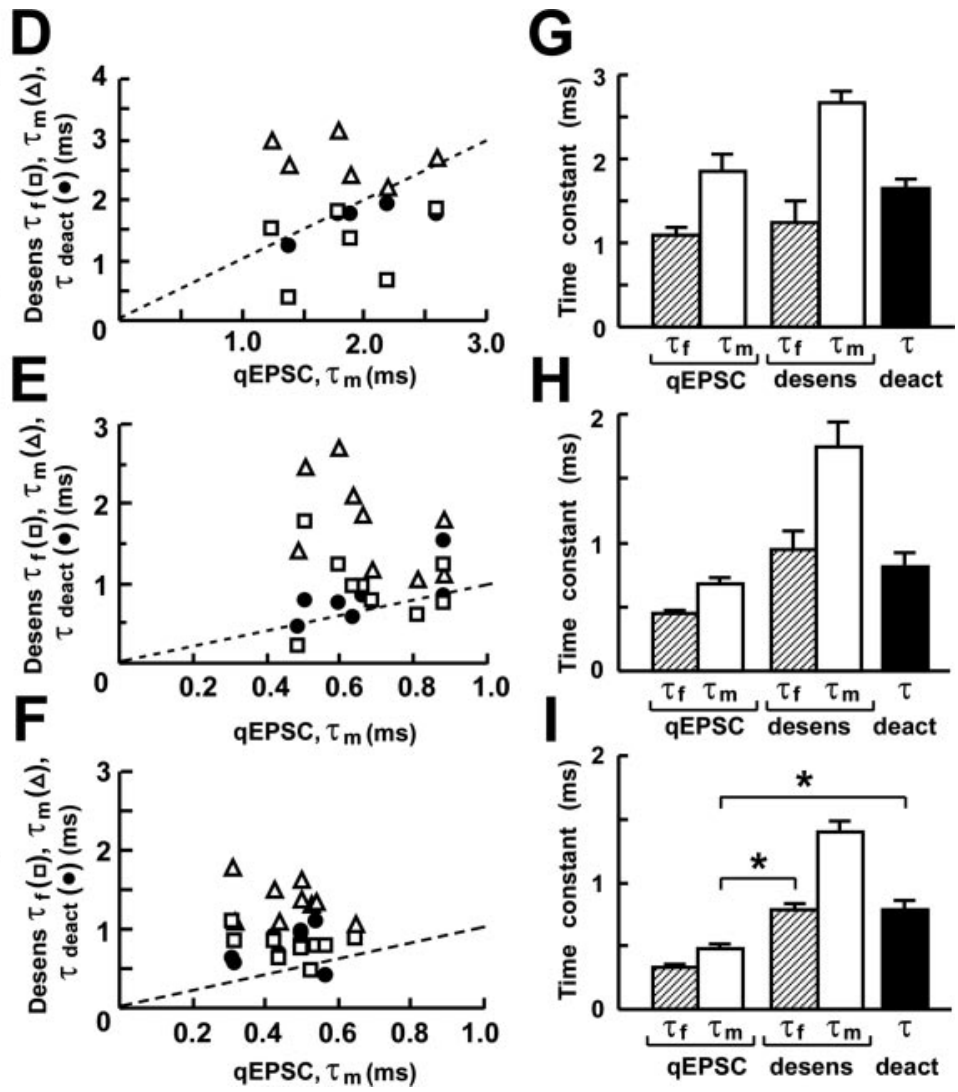

Figure 3. Comparison of desensitization and deactivation times of AMPA patch currents with the decay time of qEPSCS. A-C, Within-a-cell comparison of AMPA patch currents and qEPSCs at P6 $(A), P 14(B)$, and P21 ( () . After recording qEPSCS (left traces in A-C), an outside-out patch was excised from the same cell, and AMPAR currents were induced by fast glutamate application with long (100 msec; middle traces in $A-C$ ) and short ( 1 msec; right traces in $A-C$ ) pulses. $D-F$, Comparison between the weighted mean decay time constant of qEPSCs $\left(\tau_{\mathrm{m}} ;\right.$ abscissae) and the fast (desens $\tau_{\mathrm{f}} ;$ open squares in ordinates) and the weighted (desens $\tau_{\mathrm{m}}$; open triangles) mean time constants of desensitization or the deactivation time constant $\left(\tau_{\text {deact }}\right.$; filled circles) at P6 -P7 (D), P13-P14 $(E)$, and P20 -P21 (F). The proportion of the fast component of the qEPSCs decay time constant was 88\% (P6-P7) to 94\% (P20-P22). Equal values for ordinates and abscissae are indicated by dashed lines. G-I, Summary data at P6-P7 (G),P13-P14 ( H), and P20-P21 ( $/)$. Both the fast time constant $\left(\tau_{\mathrm{f}} ; \mathbb{C}_{2}\right)$ and the weighted mean time constant $\left(\tau_{\mathrm{m}} ; \square\right)$ are shown for the qEPSC decay time and desensitization time together with deactivation time constants $(\mathbf{\square})$. G, At P6 -P7, qEPSC $\tau_{\mathrm{f}}$ was $1.09 \pm 0.09 \mathrm{msec}$, qEPSC $\tau_{\mathrm{m}}$ was $1.85 \pm 0.20 \mathrm{msec}$, desens $\tau_{\mathrm{f}}$ was $1.25 \pm 0.25 \mathrm{msec}$, desens $\tau_{\mathrm{m}}$ was $2.66 \pm 0.15 \mathrm{msec}$, and $\tau_{\text {deact }}$ was $1.65 \pm 0.10 \mathrm{msec}(n=6)$. H, AtP13-P14, qEPSC $\tau_{\mathrm{f}}$ was $0.45 \pm 0.02 \mathrm{msec}$, qEPSC $\tau_{\mathrm{m}}$ was $0.68 \pm 0.05 \mathrm{msec}$, desens $\tau_{\mathrm{f}}$ was $0.94 \pm 0.14 \mathrm{msec}$, desens $\tau_{\mathrm{m}}$ was $1.74 \pm 0.20 \mathrm{msec}$, and $\tau_{\text {deact }}$ was $0.81 \pm 0.11 \mathrm{msec}(n=9)$. I, At P20 -P21, qEPSC $\tau_{\mathrm{f}}$ was $0.33 \pm 0.02 \mathrm{msec}, \mathrm{qEPSC} \tau_{\mathrm{m}}$ was $0.48 \pm 0.03 \mathrm{msec}$, desens $\tau_{\mathrm{f}}$ was $0.78 \pm 0.05 \mathrm{msec}$, desens $\tau_{\mathrm{m}}$ was $1.40 \pm 0.09 \mathrm{msec}$, and $\tau_{\text {deact }}$ was $0.78 \pm 0.07 \mathrm{msec}(n=9)$. The desens $\tau_{\mathrm{f}}$ was not significantly different from $\tau_{\text {deact }}$ at all ages examined (P6 $\left.-\mathrm{P} 21 ; p>0.2\right)$. The $\mathrm{EEPSC} \tau_{\mathrm{m}}$ was significantly faster than desens $\tau_{\mathrm{f}}$ and $\tau_{\text {deact }}(p<0.05$; asterisks). Data points and bars indicate mean and SEM.

from miniature EPSCs recorded in the presence of tetrodotoxin (Sahara and Takahashi, 2001; Ishikawa et al., 2002; Yamashita et al., 2003). After recording qEPSCs in the whole-cell configuration, we excised an outside-out patch from the same cell and applied glutamate using the fast application method. The decay time of qEPSCs could be well fitted by a double-exponential function as reported previously (Yamashita et al., 2003). Direct comparison between qEPSCs and AMPA patch currents in the same cell (Fig. $3 A-C$ ) indicated that the weighted mean decay time constant of qEPSCs $\left(\tau_{\mathrm{m}}\right)$ was close to the fast desensitization time constant (desens $\tau_{\mathrm{f}}$ ) as well as to the deactivation time constant $\left(\tau_{\text {deact }}\right)($ Fig. $3 D-I)$. Thus, both the fast desensitization and deactivation of AMPARs can potentially shape the decay of qEPSCs. At P20-P21, the weighted mean decay time constant of qEPSCs was faster than the fast desensitization time constant and the deactivation time constant $(p<0.05)$. This is probably caused by a technical limitation of the fast glutamate application, because the rise time (10-90\%) of AMPAR patch currents $(0.21 \mathrm{msec}$ at P20-P21) was significantly slower than that of qEPSCs $(0.13$ msec at P20-P21; $p<0.05)$.
Effect of cyclothiazide on AMPAR desensitization and deactivation

Cyclothiazide (CTZ) blocks desensitization of AMPARs (Trussell et al., 1993; Yamada and Tang, 1993), and its effect is stronger for AMPARs composed of flip-form GluR subunits (Partin et al., 1994). CTZ also slows the deactivation rate of AMPAR channels (Patneau et al., 1993). Given that the flop form of GluR is abundant in the MNTB region (Geiger et al., 1995), we examined whether CTZ affects desensitization and deactivation of AMPARs in the MNTB neurons of developing animals. In outside-out patches, CTZ $(100 \mu \mathrm{M})$ dramatically slowed desensitization of AMPAR currents at all ages of the animals examined (P6-P21) (Fig. 4A), with no significant age difference (Fig. $4 C$ ). CTZ also prolonged the deactivation time of AMPAR currents (Fig. $4 B$ ) by $60-70 \%$ with a similar magnitude of slowing throughout development (Fig. 4D).

\section{Effect of CTZ on synaptic currents}

If AMPAR desensitization alone shapes the qEPSC decay, CTZ will markedly prolong the qEPSC decay time and abolish their 
A

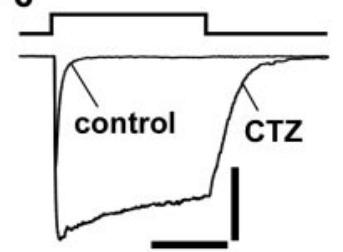

P14
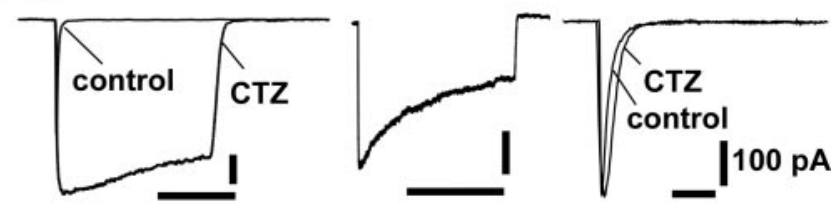

P21
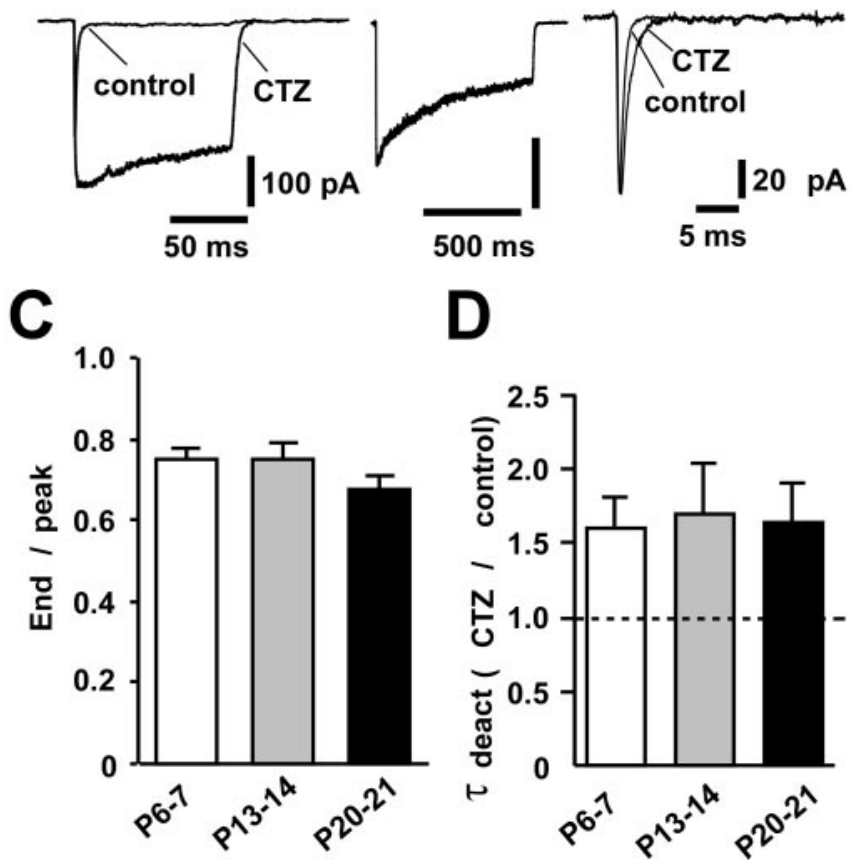

Figure 4. Effects of CTZ on AMPA patch currents at different postnatal periods. A, Effects of CTZ (100 $\mu \mathrm{M}$ ) on AMPAR desensitization induced by $100 \mathrm{msec}$ (left) or $800 \mathrm{msec}$ (right) glutamate application at P6, P14, and P21 (the 100 and 800 msec data were derived from different patches). Control AMPAR currents induced by a $100 \mathrm{msec}$ pulse before (TZ application are superimposed with those after CTZ application (left). $B$, Effects of CTZ on AMPAR deactivation after 1 msec glutamate application. The data in $A$ and $B$ were derived from different cells. C, The rate of AMPAR desensitization expressed as the mean amplitude of currents at the end of a 100 msec pulse relative to the initial amplitude (ordinate). No statistically significant difference among the values at different ages is shown. The desensitization rate at the end of a $800 \mathrm{msec}$ pulse were 0.68 (P6 -P7), 0.57 (P14), and 0.53 (P21), respectively. D, The magnitude of prolongation of the AMPAR deactivation time by CTZ: $1.60 \pm 0.21$ at P6 $-P 7(n=8), 1.70 \pm 0.35$ at P13-P14 $(n=6)$, and $1.64 \pm 0.26$ at P20-P21 $(n=7)$. Data points and bars indicate mean and SEM.

age difference in decay time kinetics. On the contrary, if AMPAR deactivation alone shapes the qEPSC decay, CTZ will uniformly prolong the qEPSC decay time by $60-70 \%$, regardless of the age of the animals. Neither of these extreme cases fitted with the results. CTZ prolonged the decay time constant of qEPSCs to $426 \pm 19 \%$ of control $(n=8)$ at P6-P7, to $265 \pm 42 \%$ at P13-P15 $(n=9)$, and to $259 \pm 19 \%$ at P20-P22 $(n=9)$ (Fig. $5 B)$. These results suggest that both deactivation and fast desensitization of AMPARs are involved in the qEPSC decay time. The most prom-
A

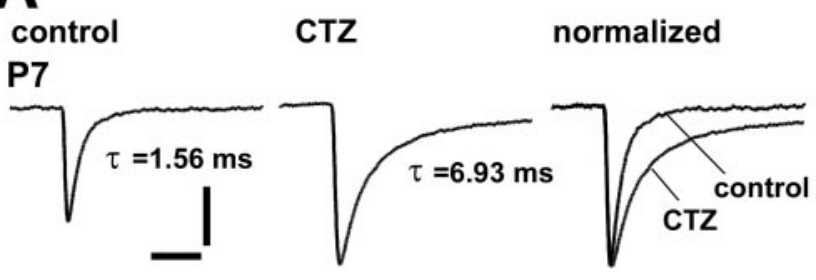

P14

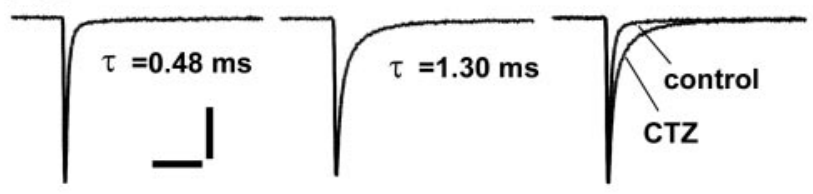

P21
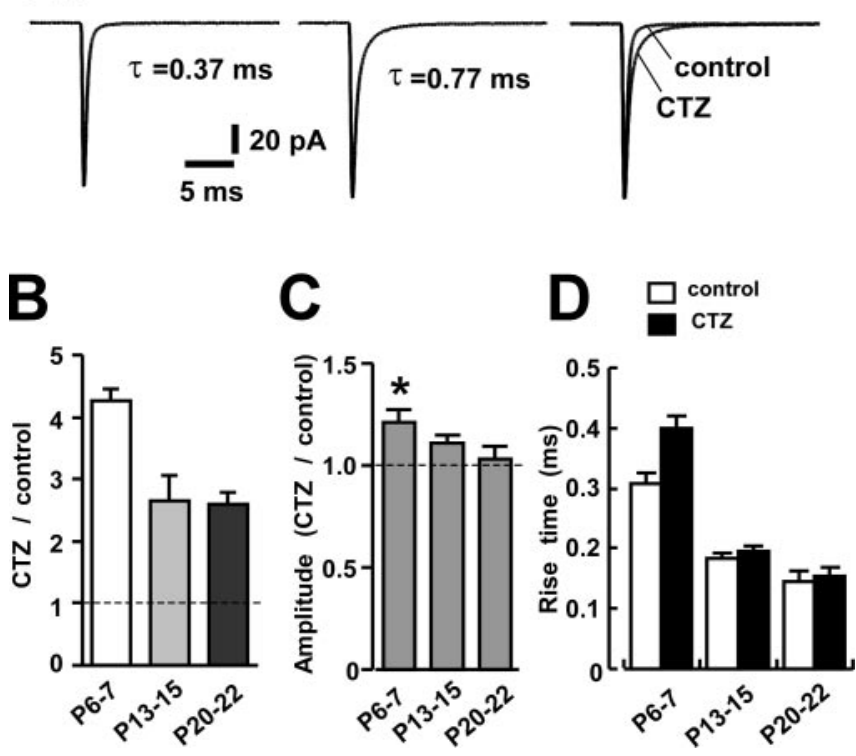

Figure 5. The effect of CTZ on qEPSCs at different postnatal periods. A, Slowings in the decay time of qEPSC by CTZ (100 $\mu \mathrm{M})$ at P7, P14, and P21. Sample records were averaged each from 183-665 qEPSCS. qEPSCs before (left traces) and after (middle traces) CTZ application are normalized at the peak amplitude and superimposed (right traces). Each value indicates the weighted mean decay time constant of averaged qEPSCS. B, The magnitude of prolongation of the qEPSCs decay time constant by CTZ at P6 $-\mathrm{P7}(4.26 \pm 0.19$ relative to control; $n=8)$, P13-P15 $(2.65 \pm 0.42 ; n=9)$, and P20-P22 $(2.59 \pm 0.19 ; n=9)$. C, The magnitude of potentiation in the qEPSC amplitude by CTZ. The potentiation was statistically significant at $\mathrm{P} 6-\mathrm{P7}(121 \pm 6 \%$ relative to control; $n=8 ; p<0.01$; asterisk; paired $t$ test) but not significant at P13-P15 $(111 \pm 4 \% ; n=8)$ and P20-P22 $(103 \pm 6 \% ; n=9)$. D, The magnitude of prolongation in the qEPSC rise time (10-90\%) by CTZ, which was statistically significant at all ages examined ( $p<0.05$; paired $t$ test). Data points and bars indicate mean and SEM.

inent prolongation of the qEPSC decay time by CTZ at P6-P7 suggests the greatest contribution of AMPAR desensitization to the qEPSC decay at this early postnatal period. Consistently, CTZ clearly potentiated the qEPSC amplitude at P6-P7 $(p<0.01$; paired $t$ test), but the potentiation became less significant as animals matured (Fig. 5C). CTZ also prolonged the rise time of qEPSCs most prominently at P6-P7 (Fig. 5D). These results suggest that subsynaptic AMPARs may undergo desensitization at the rising phase of qEPSCs at these immature synapses.

The contribution of receptor desensitization to the decay time of synaptic currents would be greater when the decay of transmitter concentration in the synaptic cleft is slower (Trussell et al., 1993; Barbour et al., 1994). Therefore, the strong slowing effect of CTZ on the qEPSC decay time at P6-P7 might arise from slow 
A

control

CTZ

normalized

P7
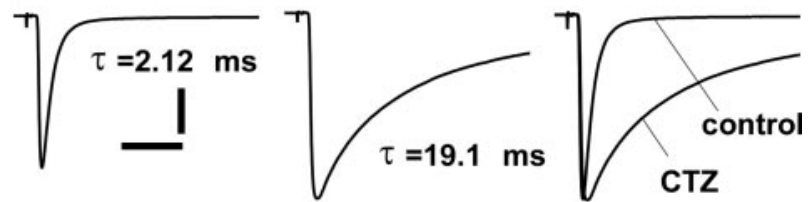

P14
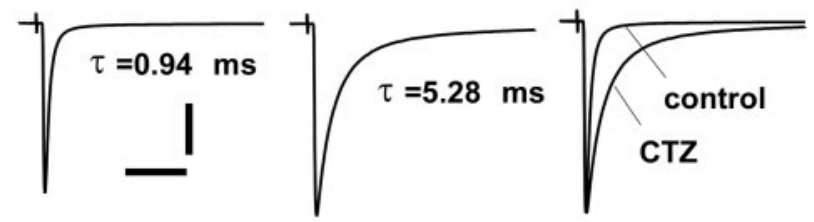

P21
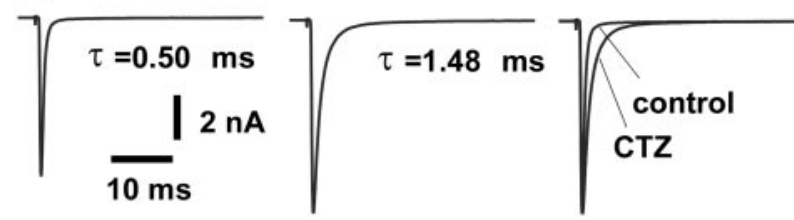

B
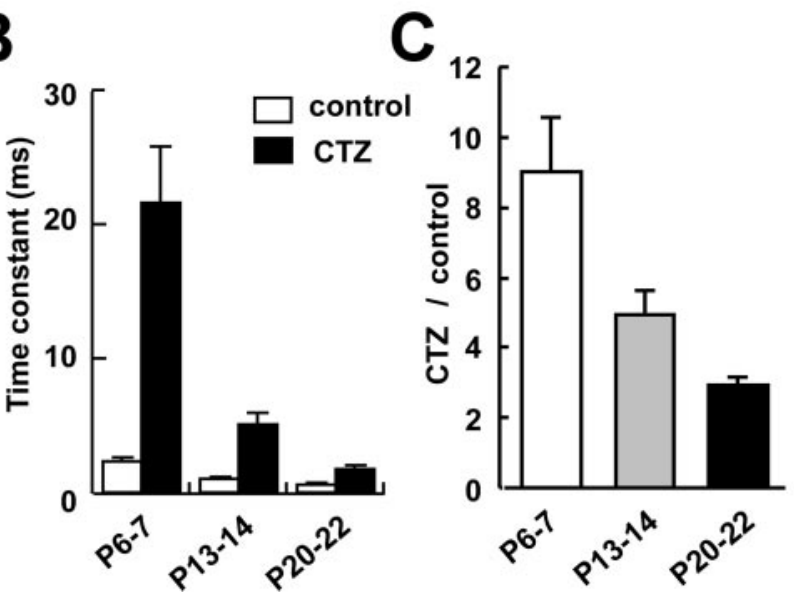

Figure 6. The effect of CTZ on nerve-evoked EPSCs at different postnatal periods. $A$, Slowings in the decay time of EPSCs by CTZ (100 $\mu \mathrm{m})$ at P7, P14, and P21. Sample records were averaged each from 10 EPSCs. Evoked EPSCs before (left traces) and after (middle traces) CTZ application are normalized at the peak amplitude and superimposed (right traces). Each value indicates the weighted mean decay time constant of averaged EPSCS. B, Summary in the weighted mean decay time constants of evoked EPSCs before $(\square)$ and after $(\square)$ CTZ application at different postnatal days. $C$, The weighted mean decay time constants $\left(\tau_{\mathrm{m}}\right)$ of evoked EPSCs after CTZ application relative to control were $9.02 \pm 1.54(n=10)$ at P6 $-P 7,4.96 \pm 0.70(n=10)$ at $\mathrm{P} 13-\mathrm{P} 15$, and $2.92 \pm 0.22(n=9)$ at P20 -P22. Data points and bars indicate mean and SEM.

clearance of transmitter from synaptic cleft at this early postnatal period. The effect of CTZ would then be stronger for evoked EPSCs arising from multiple transmitter quanta. As illustrated in Figure 6, this indeed was the case. CTZ prolonged the decay time constant of evoked EPSCs more markedly than qEPSCs at P6-P7 (increase to $902 \pm 150 \% ; p<0.001$; paired $t$ test) and at P13-P14 (to $496 \pm 70 \% ; p<0.001$; paired $t$ test), whereas the effect of CTZ on evoked EPSCs (to $291 \pm 22 \%$ ) (Fig. 6C) was similar to that on qEPSCs at P20-P22 (Fig. 5B). Given that CTZ increases transmitter release probability by inhibiting presynaptic voltagedependent potassium conductance (Ishikawa and Takahashi, 2001), it might increase asynchronous release, thereby prolonging the decay time. However, this effect does not seem to be
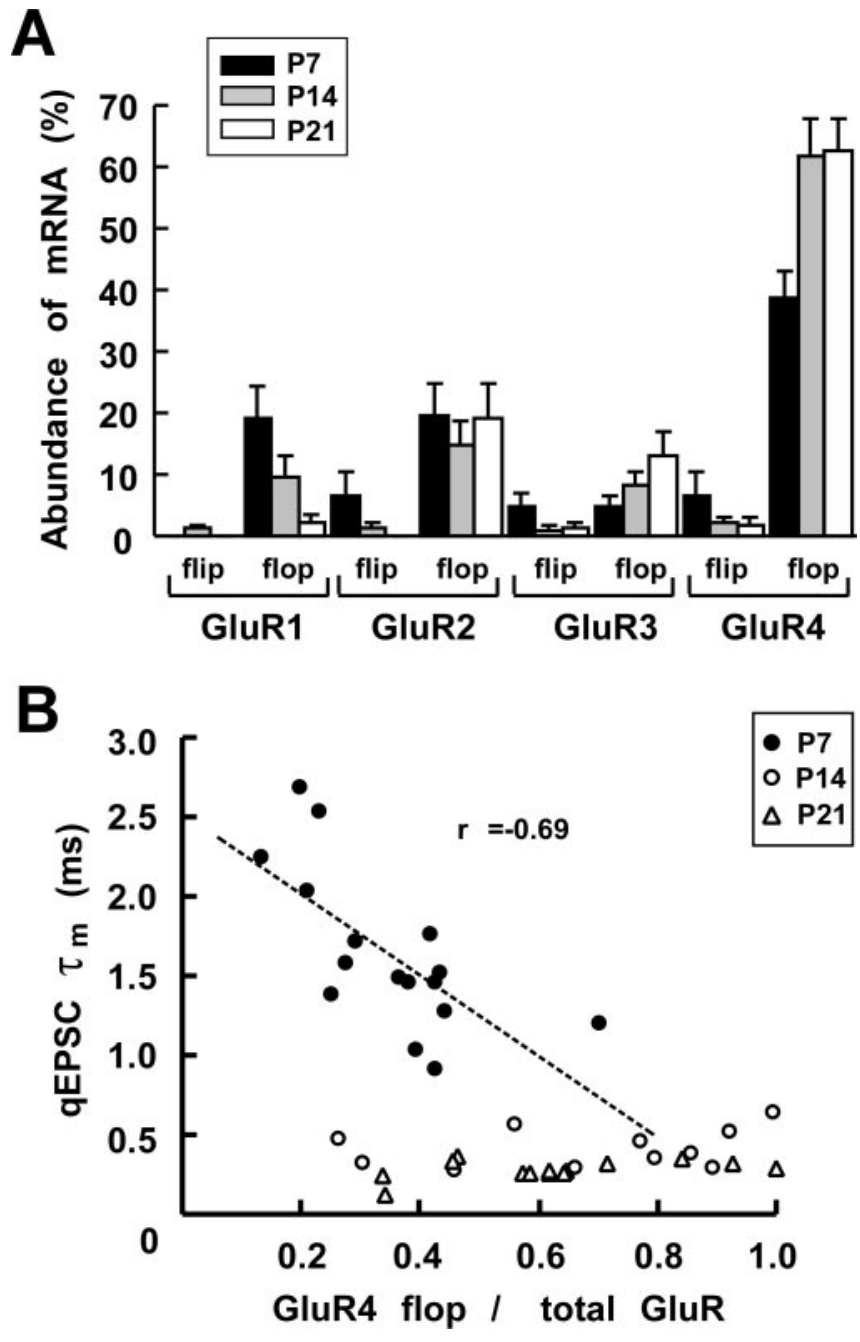

Figure 7. GluR mRNAs measured using quantitative single-cell RT-PCR at developing MNTB principal neurons. $A$, The relative amount of mRNAs encoding GluR1-GluR4 flip and flop splice

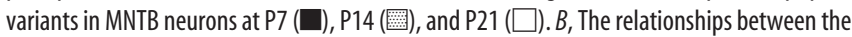
decay time constant of $q$ EPSCs (ordinate) and the abundance of GluR4 flop variants (abscissa) in individual MNTB cells at P7 (O), at P14 (○), and P21 $(\triangle)$. There was an inverse correlation between the $\mathrm{qEPSC}$ s decay time constant $\left(\tau_{\mathrm{m}}\right)$ and the abundance of GluR4 flop variants at P7 $(r=-0.69)$. No clear correlation was observed at P14 $(r=0.28)$ and P21 $(r=0.42)$. At P7, only GluR4 flop, among other GluRs, had a significant correlation with the qEPSC decay time constant ( $p<0.05$; Spearman's correlation analysis). Data points and bars indicate mean and SEM.

significant because the increase in rise time (10-90\%) of evoked EPSCs by CTZ (by 23\% at P6-P7, 9\% at P13-P15, and 14\% at P20-P22) was not larger than those of qEPSCs (Fig. 5D) (37\% at $\mathrm{P} 6-\mathrm{P} 7,10 \%$ at $\mathrm{P} 13-\mathrm{P} 15$, and $14 \%$ at $\mathrm{P} 20-\mathrm{P} 22)$.

Developmental change in the AMPAR subunit transcripts

We next examined whether the AMPAR subunits might switch during development like other ionotropic receptors (Mishina et al., 1986; Akagi and Miledi, 1988; Becker et al., 1988; Watanabe et al., 1992; Okada et al., 2000). After recording qEPSCs from MNTB neurons, intracellular contents were harvested into the patch pipette and submitted for the quantitative RT-PCR analysis (Lambolez et al., 1992). As illustrated in Figure 7A, GluR4 flop is the most abundant form of the AMPAR subunit transcript throughout development. GluR2 flop mRNA was the second most abundant form, comprising 20\% of the total GluR1-GluR4 transcripts throughout development. During postnatal development, GluR1 flop mRNA decreased, whereas GluR3 flop mRNA 
increased. With respect to the relative abundance of flip and flop mRNAs, the flop form comprised $83.6 \pm 4.9 \%(n=20)$ of the total GluR1-GluR4 mRNAs at P7 and increased to $94.7 \pm 2.0 \%$ $(n=17)$ at P14 $(p<0.05)$, with no additional increase at P21 $(96.8 \pm 1.5 \% ; n=15)$.

Recombinant AMPARs composed of GluR2 flop or GluR4 flop have a faster desensitization time than those composed of the flip form, whereas deactivation time is similar between flip- and flop-form GluRs (Mosbacher et al., 1994; Koike et al., 2000). Consistently, in neocortical neurons, the abundance of GluR flop is associated with the fast desensitization time of AMPA patch currents, whereas it is unrelated with the deactivation time (Lambolez et al., 1996). In CNS neurons, the abundance of GluR4 flop is correlated with the AMPAR desensitization time and also weakly with the deactivation time (Geiger et al., 1995). In singlecell RT-PCR analysis, we examined whether the qEPSC decay time constant is correlated with the abundance of GluR4 flop (Fig. 7B). At P7, the weighted mean decay time constant of qEPSC had a clear inverse correlation with the relative amount of GluR4 flop mRNAs $(r=-0.69)$. In contrast, at P14 and P21, there was no correlation between these parameters. These results are consistent with the idea that the contribution of AMPAR desensitization to qEPSC is high at P7 but decreases as animals mature.

\section{Discussion}

Our present results at the calyx of Held suggest that the developmental speeding in the decay of AMPA-EPSCs cannot simply be attributed to a developmental change in the AMPAR deactivation or desensitization kinetics, but that the contribution of desensitization to the EPSC decay becomes less important as animals mature. This is in agreement with what is reported at chick auditory synapses (Brenowitz and Trussell, 2001) but contrasts with the report at the cerebellar granule cell synapse, where desensitization becomes increasingly important in shaping EPSC decay as animals mature (Wall et al., 2002). This conclusion is supported by the finding that the slowing effect of CTZ on the EPSC decay decreased with development, whereas that on the AMPA patch currents remained constant throughout development. This assumes that subsynaptic and extrasynaptic AMPARs are identical, which is supported by the functionally identical dendritic and somatic GluR channels in Purkinje cells (Häusser and Roth, 1997) and also by the recent reports that subsynaptic AMPA receptors are inserted and removed by lateral diffusion via extrasynaptic receptors (Borgdorff and Choquet, 2002; Ashby et al., 2004).

\section{Developmental changes in the GluR transcripts}

Our quantitative single-cell RT-PCR study indicated that GluR4 flop is the most abundant GluR transcript in the MNTB neuron throughout development, as reported previously for these neurons in P11-P12 rats (Geiger et al., 1995). Our results further indicated that the proportion of GluR4 flop increased from P7 to P14 but remained similar thereafter. GluR2 flop was the second most abundant GluR transcript in MNTB neurons. In contrast, Joshi et al. (2004) reported that GluR2 immunoreactivity is virtually absent in MNTB neurons in mice throughout development (P5-P18). Consistent with GluR2 deficiency, in mice the current-voltage relationship of AMPA-EPSCs shows a strong rectification with little outward current in the presence of intracellular spermine in the MNTB neurons (Joshi et al., 2004). In contrast, in rats GluR2 immunoreactivity was present throughout development both in the synaptic and extrasynaptic regions of MNTB neurons (supplemental Fig. 1A, available at www.jneurosci.org as supplemental material), and the current-voltage relationship of AMPA-EPSCs with spermine was less rectified than that in mice (rectification index 0.3 at P7) (supplemental Fig. $1 \mathrm{~B}$, available at www.jneurosci.org as supplemental material). Thus, the GluR2 expression in MNTB neurons seems different between mice and rats.

Recombinant AMPARs composed of GluR4 flop (Mosbacher et al., 1994) or GluR2 flop (Koike et al., 2000) show the fastest desensitization among those composed of different GluR subunits. In the cerebral cortex, AMPAR subunit mRNAs in pyramidal cells are mostly in the flip form, and those in nonpyramidal cells are in the flop form (Lambolez et al., 1996). Consistent with recombinant studies, desensitization of the AMPA patch currents is much faster in nonpyramidal cells than in pyramidal cells (Lambolez et al., 1996). Thus, developmental increase in GluR4 flop in MNTB neurons from P7 to P14 explains the marked speeding in the AMPAR desensitization kinetics during this period (Figs. 2B, $7 A$ ). Given that the developmental speeding of AMPAR desensitization resulted from speedings of both fast and slow components with no change in their relative proportion, abundance of GluR4 flop may affect the desensitization kinetics itself, rather than the relative proportion of fast and slow desensitizing components.

At P7, CTZ prolonged the qEPSC decay by $>300 \%$ (Fig. 5), whereas it prolonged the AMPA patch current deactivation by only $60 \%$ (Fig. $4 D$ ). Furthermore, the abundance of GluR4 flop transcript was inversely correlated with the qEPSC decay time constant at P7 (Fig. 7B). Together, these suggest a significant contribution of AMPAR desensitization to the EPSC decay time at this immature period. At P14 and P21, the magnitudes of prolongation of qEPSC decay by CTZ were 165 and 159\%, respectively (Fig. 5), which were still larger than the effect of CTZ on the AMPAR deactivation at these ages (70\% at P14 and 64\% at P21) (Fig. 4D), suggesting that the AMPAR desensitization still contributes to shape the qEPSC decay after P14, albeit to a lesser extent. Because the EPSC decay time constant was close to the time constants of both fast desensitization and deactivation of AMPARs in individual MNTB neurons (Fig. 3), the EPSC decay time after P14 is likely to be shaped by both fast desensitization and deactivation of AMPARs. The GluR4 flop abundance was correlated with the qEPSC decay time only at immature synapses. Compared with GluR flip, GluR flop AMPARs have a faster desensitization time but similar deactivation time (Mosbacher et al., 1994; Koike et al., 2000). Also, the abundance of GluR flop is associated with fast desensitization but not with deactivation of the AMPA patch currents in neocortical neurons (Lambolez et al., 1996). Thus, the clear correlation between GluR4 flop abundance and the qEPSC decay time at P7 is consistent with the results of CTZ, indicating greater involvement of desensitization at immature synapses.

In recombinant AMPARs, CTZ preferentially blocks desensitization of those composed of GluR flip variants (Partin et al., 1994; Fleck et al., 1996). However, in MNTB neurons, despite abundant GluR flop variants throughout development, desensitization of AMPAR currents was dramatically reduced by CTZ. At the mouse calyx of Held, Joshi et al. (2004) postulated that a shift in the dominance of AMPAR subunit from GluR1 to GluR3/4 may account for the developmental speeding of AMPAEPSC kinetics. Although our RT-PCR results are consistent with the results of immunoreactivity by Joshi et al. (2004) regarding the developmental decrease in GluR1 and increase in GluR4, our results indicate that developmental speeding of the AMPA-EPSC 
kinetics cannot simply be attributed to the switch of AMPAR subunits.

\section{Contribution of deactivation and desensitization of AMPAR channels to EPSC decay time kinetics}

It is variable among synapses whether the EPSC decay time is shaped by desensitization or deactivation of postsynaptic AMPARs. At the avian magnocellular synapse, Otis et al. (1996b) demonstrated that multiquantal transmitter glutamate desensitizes postsynaptic AMPARs. At this synapse, desensitization is fast, and transmitter released from individual sites overlaps with each other, thereby retarding the clearance of transmitter from synaptic cleft (Trussell and Fischbach, 1989; Trussell et al., 1993). With slow clearance, transmitter can react with receptors multiple times, thereby prolonging the decay time of quantal synaptic responses (Katz and Miledi, 1973). In such a situation, fast desensitization of AMPARs can shape synaptic currents (Trussell et al., 1993; Barbour et al., 1994). In contrast, at the hippocampal, cerebral cortical, and cerebellar synapses of rodents, where transmitter clearance from synaptic cleft is fast, AMPAR deactivation shapes the decay time of qEPSCs (Colquhoun et al., 1992; Hestrin, 1992; Diamond and Jahr, 1995; Silver et al., 1996; Geiger et al., 1997).

Different speed of transmitter clearance from synaptic cleft underlies different decay times of EPSCs recorded from cerebellar Purkinje cells and interneurons (Barbour et al., 1994). Glutamate transporters contribute to transmitter clearance in chick auditory brainstem synapses (Otis et al., 1996a). At the calyx of Held (P14-P21), however, glutamate uptake inhibitors (100 $\mu \mathrm{M}$ dihydrokainic acid, $500 \mu \mathrm{M}$ L-trans-2,4-pyrrolidine-2-4dicarboxylic acid, or $100 \mu \mathrm{M}$ threo- $\beta$-benzyloxyaspartic acid) showed only a marginal slowing at the decay phase of evoked EPSCs (M. Kaneko and M. Koike-Tani, unpublished observations), suggesting that clearance of transmitter glutamate from synaptic cleft depends mainly on diffusion. Across the period of hearing onset (P9-P13) (Mikaelian and Ruben, 1964; Futai et al., 2001), the calyx of Held nerve terminal reforms its shape from spoon-shape to finger-like structure (Kandler and Friauf, 1993). These morphological changes may presumably speed up transmitter clearance from synaptic cleft, thereby decreasing the contribution of desensitization to the decay time of synaptic currents.

Another factor that enhances desensitization would be the high occupancy of AMPARs by transmitter. At the immature calyx of Held, the low-affinity AMPAR agonist kynurenate attenuates synaptic depression during repetitive stimulation at P5-P7 but not at P12-P14, suggesting that AMPAR occupancy may be greater in more immature animals (Taschenberger et al., 2002). Direct loading of glutamate into the calyceal nerve terminal also indicated higher receptor occupancy at P7 (T. Yamashita and T. Takahashi, unpublished observation) than at P14 (Ishikawa et al., 2002) or P28 (Yamashita et al., 2003). Thus, the developmental decrease in the contribution of desensitization to the decay time of synaptic currents may arise from a developmental decrease in receptor occupancy and speeding in transmitter clearance.

\section{References}

Akagi H, Miledi R (1988) Heterogeneity of glycine receptors and their messenger RNAs in rat brain and spinal cord. Science 242:270-273.

Ashby MC, De La Rue SA, Ralph GS, Uney J, Collingridge GL, Henley JM (2004) Removal of AMPA receptors (AMPARs) from synapses is preceded by transient endocytosis of extrasynaptic AMPARs. J Neurosci 24:5172-5176.

Barbour B, Keller BU, Llano I, Marty A (1994) Prolonged presence of glu- tamate during excitatory synaptic transmission to cerebellar Purkinje cells. Neuron 12:1331-1343.

Becker C-M, Hoch W, Betz H (1988) Glycine receptor heterogeneity in rat spinal cord during postnatal development. EMBO J 7:3717-3726.

Borgdorff AJ, Choquet D (2002) Regulation of AMPA receptor lateral movements. Nature 417:649-653.

Brenowitz S, Trussell LO (2001) Maturation of synaptic transmission at end-bulb synapses of the cochlear nucleus. J Neurosci 21:9487-9498.

Cathala L, Brickley S, Cull-Candy S, Farrant M (2003) Maturation of EPSCs and intrinsic membrane properties enhances precision at a cerebellar synapse. J Neurosci 23:6074-6085.

Clements JD, Bekkers JM (1997) Detection of spontaneous synaptic events with an optimally scaled template. Biophys J 73:220-229.

Colquhoun D, Jonas P, Sakmann B (1992) Action of brief pulses of glutamate on AMPA/kainite receptors in patches from different neurons of rat hippocampal slices. J Physiol (Lond) 458:261-287.

Diamond JS, Jahr CE (1995) Asynchronous release of synaptic vesicles determines the time course of the AMPA receptor-mediated EPSC. Neuron 15:1097-1107.

Fischbach GD, Schuetze SM (1980) A post-natal decrease in acetylcholine channel open time at rat end-plates. J Physiol (Lond) 303:125-137.

Fleck MW, Bähring R, Patneau DK, Mayer ML (1996) AMPA receptor heterogeneity in rat hippocampal neurons revealed by differential sensitivity to cyclothiazide. J Neurophysiol 75:2322-2333.

Forsythe ID, Barnes-Davies M (1993) The binaural auditory pathway: membrane currents limiting multiple action potential generation in the rat medial nucleus of the trapezoid body. Proc R Soc Lond B Biol Sci 251:143-150.

Futai K, Okada M, Matsuyama K, Takahashi T (2001) High-fidelity transmission acquired via a developmental decrease in NMDA receptor expression at an auditory synapse. J Neurosci 21:3342-3349.

Galarreta M, Hestrin S (2001) Spike transmission and synchrony detection in networks of GABAergic interneurons. Science 292:2295-2299.

Geiger JRP, Melcher T, Koh D-S, Sakmann B, Seeburg PH, Jonas P, Monyer H (1995) Relative abundance of subunit mRNAs determines gating and $\mathrm{Ca}^{2+}$ permeability of AMPA receptors in principal neurons and interneurons in rat CNS. Neuron 15:193-204.

Geiger JRP, Lubke J, Roth A, Frotscher M, Jonas P (1997) Submillisecond AMPA receptor-mediated signaling at a principal neuron-interneuron synapse. Neuron 18:1009-1023.

Häusser M, Roth A (1997) Dendritic and somatic glutamate receptor channels in rat cerebellar Purkinje cells. J Physiol (Lond) 501:77-95.

Hestrin S (1992) Activation and desensitization of glutamate-activated channels mediating fast excitatory synaptic currents in the visual cortex. Neuron 9:991-999.

Ishikawa T, Takahashi T (2001) Mechanisms underlying presynaptic facilitatory effect of cyclothiazide at the calyx of Held of juvenile rats. J Physiol (Lond) 533:423-431.

Ishikawa T, Sahara Y, Takahashi T (2002) A single packet of transmitter does not saturate postsynaptic glutamate receptors. Neuron 34:613-621.

Iwasaki S, Takahashi T (2001) Developmental regulation of transmitter release at the calyx of Held in rat auditory brainstem. J Physiol (Lond) 534:861-871.

Joshi I, Wang L-Y (2002) Developmental profiles of glutamate receptors and synaptic transmission at a single synapse in the mouse auditory brainstem. J Physiol (Lond) 540:861-873.

Joshi I, Shokralla S, Titis P, Wang L-Y (2004) The role of AMPA receptor gating in the development of high-fidelity neurotransmission at the calyx of Held synapse. J Neurosci 24:183-196.

Kandler K, Friauf E (1993) Pre- and postnatal development of efferent connections of the cochlear nucleus in the rat. J Comp Neurol 328:161-184.

Katz B, Miledi R (1973) The binding of acetylcholine to receptors and its removal from the synaptic cleft. J Physiol (Lond) 231:549-574.

Koike M, Tsukada S, Tsuzuki K, Kijima H, Ozawa S (2000) Regulation of kinetic properties of GluR2 AMPA receptor channels by alternative splicing. J Neurosci 20:2166-2174.

Lambolez B, Audinat E, Bochet P, Crépel F, Rossier J (1992) AMPA receptor subunits expressed by single Purkinje cells. Neuron 9:247-258.

Lambolez B, Ropert N, Perrais D, Rossier J, Hestrin S (1996) Correlation between kinetics and RNA splicing of $\alpha$-amino-3-hydroxy-5methylisoxazole-4-propionic acid receptors in neocortical neurons. Proc Natl Acad Sci USA 93:1797-1802. 
Magleby KL, Stevens CF (1972) A quantitative description of end-plate currents. J Physiol (Lond) 223:173-197.

Mikaelian D, Ruben RJ (1964) Development of hearing in the normal CBA-J mouse. Acta Otolaryngol 59:451-461.

Mishina M, Takai T, Imoto K, Noda M, Takahashi T, Numa S, Methfessel C, Sakmann B (1986) Molecular distinction between fetal and adult forms of muscle acetylcholine receptor. Nature 321:406-411.

Monyer H, Burnashev N, Laurie DJ, Sakmann B, Seeburg PH (1994) Developmental and regional expression in the rat brain and functional properties of four NMDA receptors. Neuron 12:529-540.

Mosbacher J, Schoepfer R, Monyer H, Burnashev N, Seeburg PH, Ruppersberg JP (1994) A molecular determinant for submillisecond desensitization in glutamate receptors. Science 266:1059-1062.

Okada M, Onodera K, Van Renterghem C, Sieghart W, Takahashi T (2000) Functional correlation of $\mathrm{GABA}_{\mathrm{A}}$ receptor $\alpha$ subunits expression with the properties of IPSCs in the developing thalamus. J Neurosci 20:2202-2208.

Otis T, Wu Y-C, Trussell LO (1996a) Delayed clearance of transmitter and the role of glutamate transporters at synapses with multiple release sites. J Neurosci 16:1634-1644.

Otis T, Zhang S, Trussell LO (1996b) Direct measurement of AMPA receptor desensitization induced by glutamatergic synaptic transmission. J Neurosci 16:7496-7504.

Partin KM, Patneau DK, Mayer ML (1994) Cyclothiazide differentially modulates desensitization of $\alpha$-amino-3-hydroxy-5-methyl-4-isoxazolepropionic acid receptor splice variants. Mol Pharmacol 46:129-138.

Patneau DK, Vyklicky Jr L, Mayer ML (1993) Hippocampal neurons exhibit cyclothiazide-sensitive rapidly desensitizing responses to kainate. J Neurosci 13:3496-3509.

Raman IM, Trussell LO (1995) The mechanism of $\alpha$-amino-3-hydroxy-5methyl-4-isoxazolepropionate receptor desensitization after removal of glutamate. Biophys J 68:137-146.

Sahara Y, Takahashi T (2001) Quantal components of the excitatory postsynaptic currents at a rat central auditory synapse. J Physiol (Lond) 536:189-197.

Sakmann B, Brenner HR (1978) Change in synaptic channel gating during neuromuscular development. Nature 276:401-402.

Silver RA, Colquhoun D, Cull-Candy SG, Edmonds B (1996) Deactivation and desensitization of non-NMDA receptors in patches and the time course of EPSCs in rat cerebellar granule cells. J Physiol (Lond) 493:167-173.

Singer JH, Talley EM, Bayliss DA, Berger AJ (1998) Development of glycinergic synaptic transmission to rat brain stem motoneurons. J Neurophysiol 80:2608-2620.

Takahashi T, Momiyama A, Hirai K, Hishinuma F, Akagi H (1992) Functional correlation of fetal and adult forms of glycine receptors with developmental changes in inhibitory synaptic receptor channels. Neuron 9:1155-1161.

Takahashi T, Feldmeyer D, Suzuki N, Onodera K, Cull-Candy SG, Sakimura K, Mishina M (1996) Functional correlation of NMDA receptor $\epsilon$ subunits expression with the properties of single-channel and synaptic currents in the developing cerebellum. J Neurosci 16:4376-4382.

Taschenberger H, von Gersdorff H (2000) Fine-tuning an auditory synapse for speed and fidelity: developmental changes in presynaptic waveform, EPSC kinetics, and synaptic plasticity. J Neurosci 20:9162-9173.

Taschenberger H, Leão RM, Rowland KC, Spirou GA, von Gersdorff H (2002) Optimizing synaptic architecture and efficiency for highfrequency transmission. Neuron 36:1127-1143.

Trussell LO, Fischbach GD (1989) Glutamate receptor desensitization and its role in synaptic transmission. Neuron 3:209-218.

Trussell LO, Zhang S, Raman IM (1993) Desensitization of AMPA receptors upon multiquantal neurotransmitter release. Neuron 10:1185-1196.

Wall MJ, Robert A, Howe JR, Usowicz MM (2002) The speeding of EPSC kinetics during maturation of a central synapse. Eur J Neurosci 15:785-797.

Watanabe M, Inoue Y, Sakimura K, Mishina M (1992) Developmental changes in distribution of NMDA receptor channel subunit mRNAs. NeuroReport 3:1138-1140.

Yamada KA, Tang C-M (1993) Benzothiadiazides inhibit rapid glutamate receptor desensitization and enhance glutamatergic synaptic currents. J Neurosci 13:3904-3915.

Yamashita T, Ishikawa T, Takahashi T (2003) Developmental increase in vesicular glutamate content dose not cause saturation of AMPA receptors at the calyx of Held synapse. J Neurosci 23:3633-3638. 